\title{
ARTE RUPESTRE NO PARANÁ: NOVAS DISCUSSÕES
}

\author{
Claudia Inês Parellada ${ }^{1}$
}

\section{RESUMO}

No Paraná, sul do Brasil, já foram caracterizados cerca de cento e cinquenta sítios arqueológicos com pinturas rupestres e vinte com gravuras, sendo que alguns possuem as duas manifestações estéticas. Documentou-se arte rupestre em todo o território paranaense, desde a costa litorânea até o oeste, concentrando-se as pinturas na região centro-leste, em abrigos e cavernas areníticas, mas aparecendo também em diferentes litologias, como granitos e basaltos, entre outras. As gravuras rupestres no Paraná localizam-se principalmente nas margens do rio Iguaçu, e no vale do Paranapanema, em áreas de afloramentos de basaltos e andesitos da Formação Serra Geral, de arenitos e conglomerados da Formação Furnas e de arenitos e diamictitos do Grupo Itararé, além de estarem presentes em rochas ígneas e metamórficas do litoral paranaense. A documentação de sítios rupestres com painéis complexos no Paraná, e com elementos da flora, mostrou a necessidade de serem ampliadas as discussões teóricas e metodológicas de estudos arqueológicos regionais. A sistematização das informações relativas à arte rupestre em diferentes municípios do Paraná trouxe novas perspectivas para a análise dos contextos estéticos, espaciais e novas estratégias de gerenciamento e conservação deste patrimônio arqueológico, inclusive em sítios situados em unidades de conservação.

Palavras-chave: Arqueologia do Paraná, Arqueologia pré-histórica, Arte rupestre, Pinturas rupestres.

\section{INTRODUÇÃO: A ARTE RUPESTRE NO PARANÁ}

No Estado do Paraná foram descritos, entre relatos de cronistas e estudos de diferentes pesquisadores, cerca de cento e cinquenta sítios arqueológicos com pinturas rupestres e vinte com gravuras, sendo que alguns possuem ambas as manifestações estéticas. Os sítios rupestres são mais frequentes em alguns municípios paranaenses que abrangem áreas dos Campos Gerais, como Ponta Grossa, Tibagi, Piraí do Sul, Jaguariaíva, Ventania e Sengés.

Novos estudos revelaram abrigos areníticos com painéis diferenciados, tanto com mais de cem figuras humanas (Figura 1), como com representações de plantas cultivadas (ver figura 2), como apontado em Parellada et al. (2014). Assim, ampliou-se

\footnotetext{
${ }^{1}$ Museu Paranaense. E-mail: parelladaclau@ig.com.br.
} 
a revisão de dados sobre a arte rupestre no Paraná para buscar novas estratégias de pesquisa, inclusive com a utilização de métodos arqueométricos e diferentes recursos digitais para a documentação de imagens.

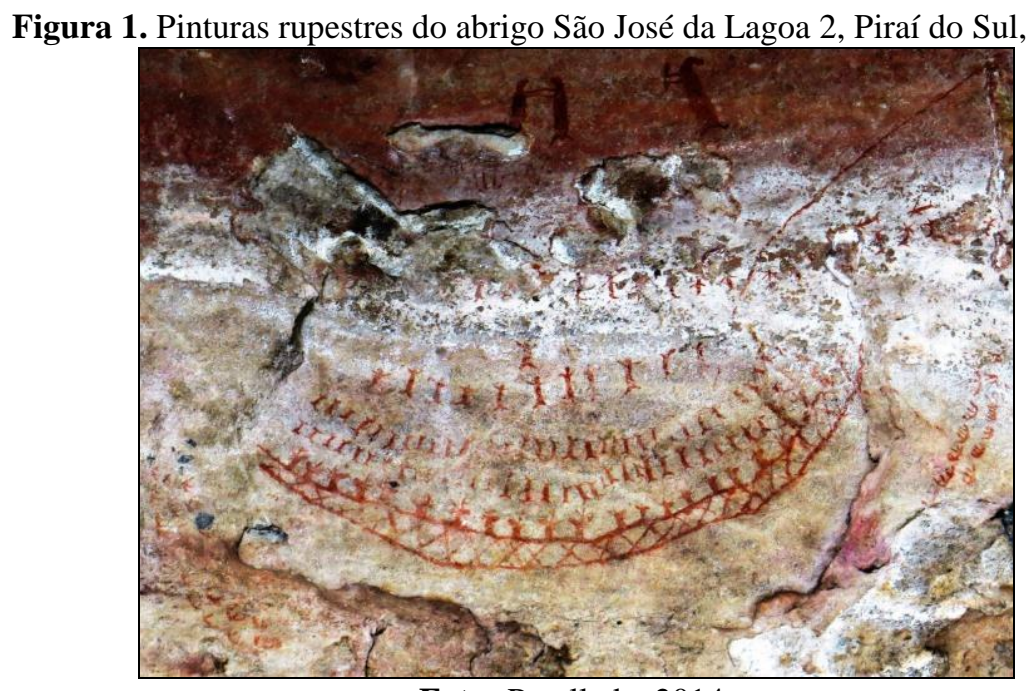

Foto: Parellada, 2014

Figura 2. Pintura de planta no Abrigo Cachoeira Bico do Pato 1, município de Tibagi, Paraná.

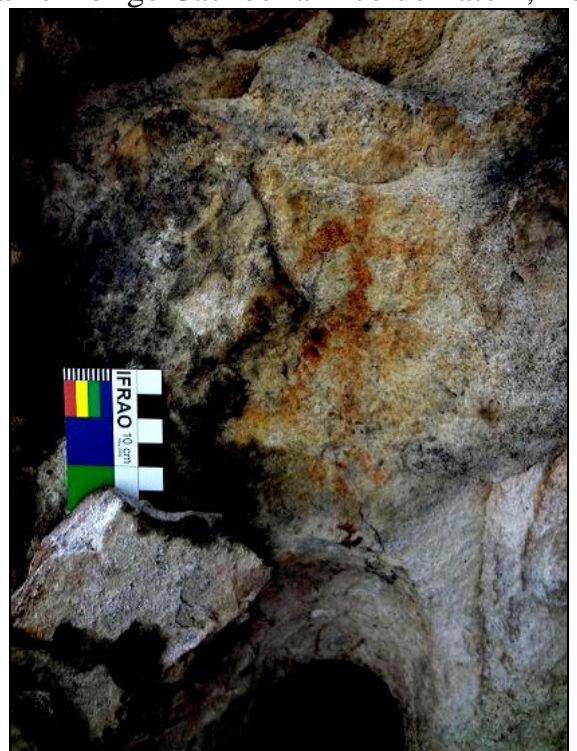

Foto. Parellada, 2014.

Existem várias publicações sobre sítios rupestres no Paraná, tais como: Laming e Emperaire (1956), Laming-Emperaire (1962; 1968), Blasi (1970; 1972), Chmyz (1976), Maranhão e Parellada (1991), Blasi et al. (1991; 2002), Parellada (1993a,b; 1997; 2001; 2003; 2006; 2008; 2009; 2010; 2013; 2014), Gottardi Neto (1995), Lima e Justo (2002), Arnt (2002), Cavalheiro (2003), Barbosa (2004), Naumes e Spoladore (2005), Silva et 
al. (2005; 2011), Gaissler (2007), Chmyz et al. (2008), Pereira (2009; 2011), Gomes (2011), Parellada et al. (1996; 2014) e Oliveira (2014).

Existe o registro de arte rupestre em todo o território paranaense, da costa litorânea até o oeste, concentrando-se as pinturas nos Campos Gerais, em cavernas e abrigos areníticos em áreas de campos e cerrados na região centro-leste, e aparecendo também em várias litologias, como granitos e basaltos, entre outras. As gravuras no Paraná localizam-se principalmente nas margens do rio Iguaçu, e no vale do Paranapanema, em áreas de afloramentos de basaltos e andesitos Serra Geral, de arenitos e conglomerados Furnas e de arenitos e diamictitos Itararé.

As informações sobre estes sítios rupestres eram bastante heterogêneas e dispersas, o que dificultava as análises comparativas e regionais, e o aprofundamento de questões teóricas e metodológicas, inclusive em relação à distribuição espacial destes sítios arqueológicos. A falta de sistematização prejudicava a proteção dessas áreas e dificultava a seleção de alternativas adequadas para conservar estes sítios, inclusive o monitoramento por sensoriamento remoto.

Assim, foi criado um banco de dados no Museu Paranaense, através de análise de extensa documentação, inclusive imagética, e com diferentes abordagens metodológicas, inclusive a arqueometria. A sistematização trouxe novas perspectivas para a análise dos contextos estéticos, espaciais e estratégias de gerenciamento e conservação do patrimônio arqueológico.

Considera-se arte rupestre como uma forma de comunicação através de convenções, ou seja, um tipo de linguagem simbólica organizada; uma estratégia de se relacionar com as pessoas e através do tempo. Vialou (1999; 2000) destaca que a arte rupestre é uma marca muito importante da originalidade simbólica, que se reflete e se define na extensão territorial em que ocorre. Assim, as pinturas e gravuras espelham a identidade cultural da sociedade que as fez, tratando-se de uma expressão da consciência simbólica coletiva.

Um estudo muito abrangente em Çatalhoyuk, Turquia, foi coordenado por Hodder (2010), correlacionando os vestígios materiais às diferentes representações simbólicas. 
As representações podem ser figurativas ou geométricas abstratas (sinais), e as quatro grandes categorias de representação da arte rupestre são as figuras humanas, de fauna, de flora e os sinais. Os sinais são representações geométricas, não importando o significado. Existem sinais elementares, como os pontos, traços, barras, e os sinais elaborados feitos a partir da reunião de sinais simples. Os sinais elaborados repetem-se, e podem ajudar a definir culturas e territórios, juntamente com a cronologia. Os motivos são representações únicas e diferenciadas, que não se repetem, e assim podem definir um sítio arqueológico específico.

A caracterização de territórios pode ser evidenciada quando se possui contextos arqueológicos melhor definidos, além dos dados documentados na arte rupestre, com sequências estratigráficas e cronológicas disponíveis, análise lítica e/ ou cerâmica, de vestígios ósseos humanos e de animais, de evidências antracológicas, entre outras possibilidades.

A arte rupestre possibilitou tanto a marcação das relações objetivas entre homens e mulheres, quanto das relações expressivas entre homens e animais. Existe uma universalidade do comportamento simbólico na arte pré-histórica, apesar de ser infinita a diversidade cultural dos grupos humanos. $\mathrm{O}$ aspecto universal decorre que a espécie humana possui uma mesma organização cerebral, e isso acaba levando a convergências. Afinal, o cérebro tem possibilidades limitadas de criar figuras.

Neste estudo foram utilizados os enfoques da arqueologia pós-processual, onde o interesse pela estrutura, mente e significado leva a uma maior preocupação pela presença da atualidade no passado (HODDER, 1988; TRIGGER, 2004). Afinal, as leituras informam e contribuem para o presente através de uma valoração crítica do passado.

Preucel e Hodder (1996) observam que a arqueologia não é o estudo do objeto, mas de processos de debate, de fazer e comunicar em diferentes perspectivas, surgidos com a evidência material. Em novas abordagens, Preucel (2006) discute a semiótica na arqueologia, ampliando as possibilidades interpretativas.

Sítios arqueológicos com características similares, para serem mais bem compreendidos, foram classificados em tradições, ainda usadas nas discussões regionais. As tradições já caracterizadas no Paraná são: Paleoíndios, Umbu, Humaitá e Sambaqui, 
relacionadas a povos caçadores-coletores, e Itararé-Taquara e a Tupiguarani, relativas a agricultores e ceramistas. Para as pinturas e gravuras rupestres, no sul do Brasil, diferentes publicações apontam as tradições Planalto e Geométrica. É importante observar que, muitas vezes, somente a arte rupestre foi documentada e analisada, e não houve contextualização de vestígios materiais e/ ou estratigráficos, devido às estratégias selecionadas nas pesquisas e/ ou, mesmo, das condições de conservação dos vestígios arqueológicos.

O patrimônio arqueológico foi incluído na Constituição Federal Brasileira, de 1988, como parte do patrimônio cultural nacional e no artigo 20, inciso X, as cavernas naturais subterrâneas e os sítios arqueológicos foram declarados bens da União.

As pesquisas arqueológicas no Brasil seguem a lei 3924 de 1961, que dispõe sobre os locais pré-históricos e históricos, e a resolução 1 de 1986 do Conselho Nacional de Meio-Ambiente (CONAMA), que prevê estudos arqueológicos em áreas de construção de grandes obras. A portaria número 7 do Instituto do Patrimônio Histórico e Artístico Nacional (IPHAN), de dezembro de 1988, define os critérios para permissões de pesquisas arqueológicos e temas relacionados, aprofundados em 2002 com a portaria 230 do mesmo órgão, posteriormente ampliada tornando obrigatórias as atividades conjuntas de educação patrimonial.

\section{Algumas PESQUiSAS COM ARTE RUPESTRE NO PARANÁ RELACIONADAS AO MUSEU PARANAENSE}

No Paraná, os primeiros estudos sistemáticos em abrigos com pinturas foram desenvolvidos pelos arqueólogos franceses Laming e Emperaire, em 1954, em Piraí do Sul e Tibagi, centro-leste paranaense. Blasi (1972) intensificou os trabalhos na região, escavando a Lapa Floriano, e documentando sítios no vale do Iapó.

Em 1970, foi pesquisado em Sengés o abrigo do Pontão, em arenito, com pinturas geométricas em vermelho, além de materiais líticos e faunísticos, cerâmica Itararé-Taquara e colonial, e remanescentes ósseos de doze indivíduos: sete adultos e cinco crianças (BLASI, 1972). Parellada e Gottardi Neto (1991) apontam duas ocupações na área, a primeira por caçadores-coletores Umbu, e a segunda por ceramistas 
Itararé-Taquara em época colonial, que teriam sepultado os mortos junto ao abrigo. Em 1990, foram caracterizados mais cinco abrigos areníticos com pinturas no nordeste paranaense: Janela e Lajeado Grande I, II e III, no município de Sengés, e Mariano, no município de Jaguariaíva. As equipes do Museu Paranaense vêm desenvolvendo pesquisas contínuas nos Campos Gerais do Paraná: Blasi (1972), Maranhão e Parellada (1991), Parellada (1993a,b; 2003; 2006; 2009; 2014) e Appoloni et al. (2011; 2014a,b).

Nas Cavernas de Morro Azul, situadas em Ventania, foram identificadas pelo menos três fases de ocupação: a mais antiga por grupos Umbu, e duas outras por ceramistas Itararé-Taquara (PARELLADA, 1993a,b). Nesse local ocorre o maior conjunto de painéis com pinturas rupestres no Paraná, sendo a rocha suporte os arenitos e diamictitos Itararé (ver figura 3), e havendo representações em vermelho e preto de seres fantásticos, máscaras, figuras humanas e de animais, círculos e semicírculos raiados, círculos grandes com traços verticais e horizontais, bastonetes, entre outros. Também existem bacias de polimento e afiadores em um grande bloco rochoso nas proximidades dos abrigos e cavernas de Morro Azul. Caracterizou-se a composição dos pigmentos vermelhos de algumas pinturas através de análise por equipamentos portáteis de fluorescência por raio $\mathrm{X}$ e espectrometria Raman, relacionados a hematita e derivados, e o pigmento preto é rico em manganês (APPOLONI et al., 2011).

Figura 3. Cavernas de Morro Azul, Ventania, Paraná.

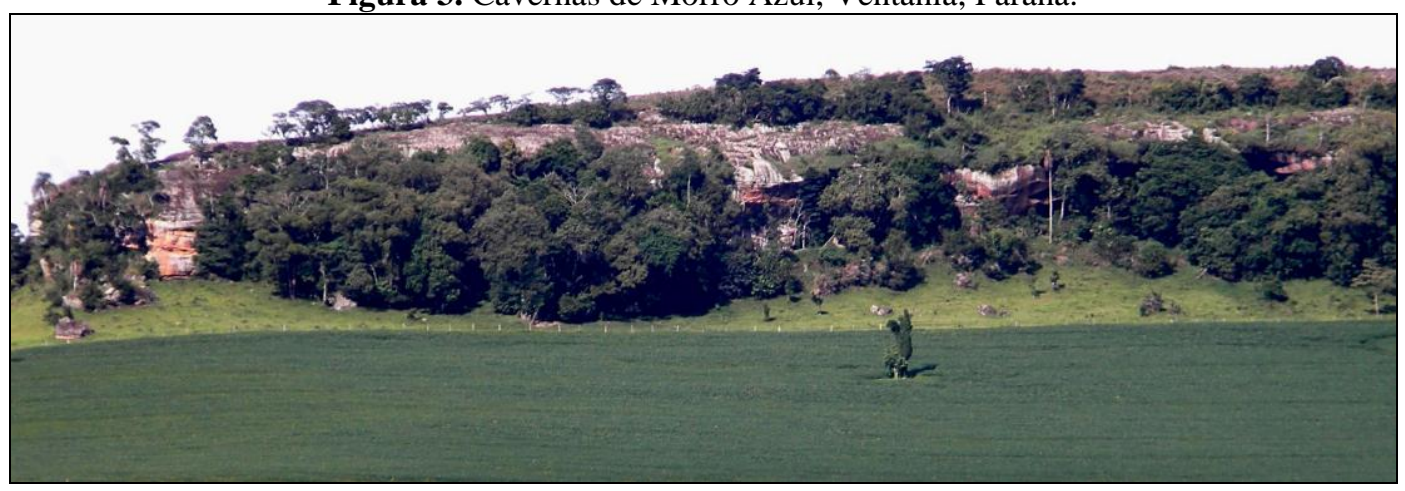

Foto: Parellada, 2011.

Em 1993, o abrigo arenítico Ponte do Rio Cajuru foi caracterizado em base de vertente, no município de Sengés, com círculo raiado em vermelho escuro (PARELLADA, 1994). 
Silva et al. (2007) descrevem o abrigo arenítico Usina São Jorge, no município paranaense de Ponta Grossa, que possui muitas pinturas rupestres, principalmente figuras de animais, cervídeos e aves em movimento, além de poucas representações geométricas, e onde ocorre cerâmica Itararé-Taquara superficial.

O Abrigo Três Amigos I, em granito, município de Cerro Azul, nordeste do Paraná, possui pinturas em marrom e vermelho, predominando figuras de animais, como cervídeos, répteis, além de representações geométricas. As pinturas estão apagadas, provavelmente devido à infiltração de água e o tipo de fixador (PARELLADA, 2006).

Parellada orientou monografia de Lima e Justo (2002), da UEPG, sobre aspectos pré-coloniais e históricos do rio Iapó, inclusive discutindo o imaginário da comunidade local.

Na projeto das Linhas de Transmissão em 230kV entre Bateias e Jaguariaíva, entre 2002 e 2004, foram cadastrados mais dois abrigos com pinturas em Jaguariaíva: Butiá 1 e Jaguariaíva 1. As pinturas são em vermelho, marrom e amarelo, no Butiá 1 existem círculos e grades, e no Jaguariaíva 1, figuras de animais, como cervídeos, além de sinais, como bastonetes, entre outros. Em 1990, caracterizaram-se mais cinco abrigos areníticos com pinturas no nordeste paranaense: Janela e Lajeado Grande I, II e III, em Sengés, e Mariano, em Jaguariaíva.

\section{A ARTE RUPESTRE NA ARQUEOLOGIA REGIONAL NO PARANÁ}

Os abrigos e cavernas com pinturas têm como rocha suporte os arenitos e conglomerados Furnas, os arenitos e diamictitos Itararé, além de granitos e basaltos (PARELLADA, 2003, 2009). A maioria das pinturas rupestres paranaenses aparece junto a afloramentos do arenito Furnas nas regiões centro-leste e nordeste do Paraná, nos vales dos rios Iapó e Tibagi, e seus afluentes. Também ocorrem junto ao alto rio Ribeira, nos vales dos rios das Cinzas, São Jorge, Jaguaricatu e Itararé, e ainda na escarpa de São Luiz do Purunã, próximo à Ponta Grossa. Neste trabalho estão enfocados especialmente os sítios arqueológicos com arte rupestre pesquisados por equipes vinculadas ao Museu Paranaense. 
A maioria das pinturas e gravuras rupestres no Paraná foi documentada em paredes e tetos e de abrigos e cavernas areníticas nos Campos Gerais no Segundo Planalto Paranaense, mas também em afloramentos e abrigos nas rochas básicas do Terceiro Planalto e em granitos e rochas metamórficas do litoral e do Primeiro Planalto, são relacionadas a diferentes povos que habitaram o território paranaense desde períodos anteriores a dez mil anos até o século XVIII. No vale do baixo Iguaçu, no sítio Ouro Verde I, sudoeste paranaense, foi documentado cerca de 500 gravuras em basaltos e andesitos, a maioria círculos com pontos centrais e provável representação astronômica (ver figura 4). Parte dessas gravuras pode estar relacionada a uma das ocupações mais antigas do Paraná, o nível inferior do sítio Ouro Verde I, datado em 9040 400 anos AP (ANU 192-17), relacionado a caçadores-coletores Umbu. Nesse sítio também ocorrem vestígios mais recentes de ceramistas Itararé-Taquara, datados em cerca de 300 anos atrás (PARELLADA, 2006).

Figura 4. Algumas gravuras rupestres de Ouro Verde, Boa Esperança do Iguaçu, Paraná.

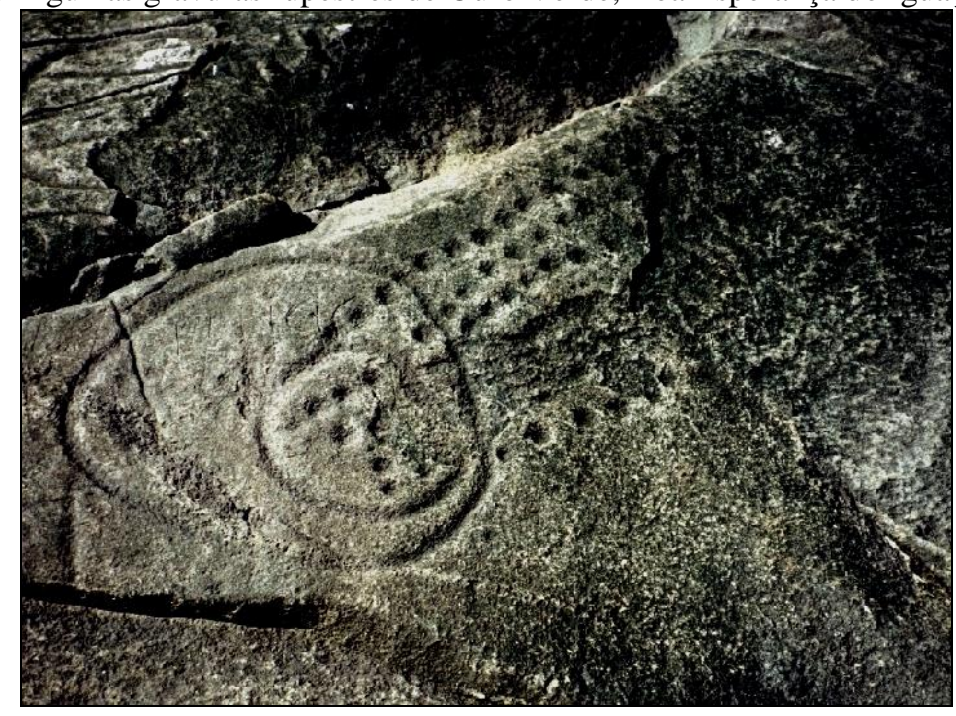

Foto: Parellada, 1997.

Ocupações Umbu bastante antigas foram identificadas no nível 135 a $145 \mathrm{~cm}$ do abrigo Tunas, em Arapoti, em $9630 \pm 40$ anos AP, e no nível entre 265 e $280 \mathrm{~cm}$ do sítio Ribeirão Barra Grande 3, em Sapopema, com $9190 \pm 60$ anos AP (CHMYZ et al., 2008).

Moro (2012) estudou áreas de cerrado nos Campos Gerais discutindo a relação entre sítios arqueológicos e remanescentes botânicos, buscando evidenciar populações 
relacionadas a ambientes diferenciados, associadas a épocas mais recuadas, com climas mais secos.

Os planaltos do sul do Brasil, há 7.400 anos cal AP, estavam dominados por campos, em clima mais frio e seco que o atual, e as araucárias provavelmente se restringiam a vales fechados e profundos e vertentes costeiras mais úmidas. Posteriormente a 4.320 anos cal AP as araucárias se expandiram em redes de matas de galeria (BEHLING et al., 2004).

Grande parte das pinturas rupestres no Paraná se caracteriza pela presença de figuras de animais associadas a sinais geométricos, além de seres humanos, em tons vermelhos, marrons e pretos, e raras pinturas em amarelo. Alguns animais foram representados em fila, de perfil, associados a grades, vistos de cima ou de frente, e alguns muito esquematizados. Já foram caracterizadas três fases de pinturas rupestres nos Campos Gerais do Paraná, como no abrigo Chapadinha 1, em Piraí do Sul, sendo a mais antiga, caracterizada por figuras de animais, algumas grandes, com frequência cervídeos chapados, ou seja, pintados integralmente, e associados com grades e outros elementos. A segunda fase, com pinturas geométricas abstratas, geralmente em vermelho, marrom e amarelo, como pontos, círculos e traços, em diferentes tamanhos e espessuras, algumas vezes compõe linhas e desenhos, associadas a figuras humanas e de animais. Uma terceira fase, com silhuetas de animais pintadas em vermelho escuro, e com o interior preenchido por traços que se cruzam, sendo os cervídeos recorrentes (ver figura 5).

Figura 5. Painel com superposições no abrigo Chapadinha 1, Piraí do Sul, Paraná.

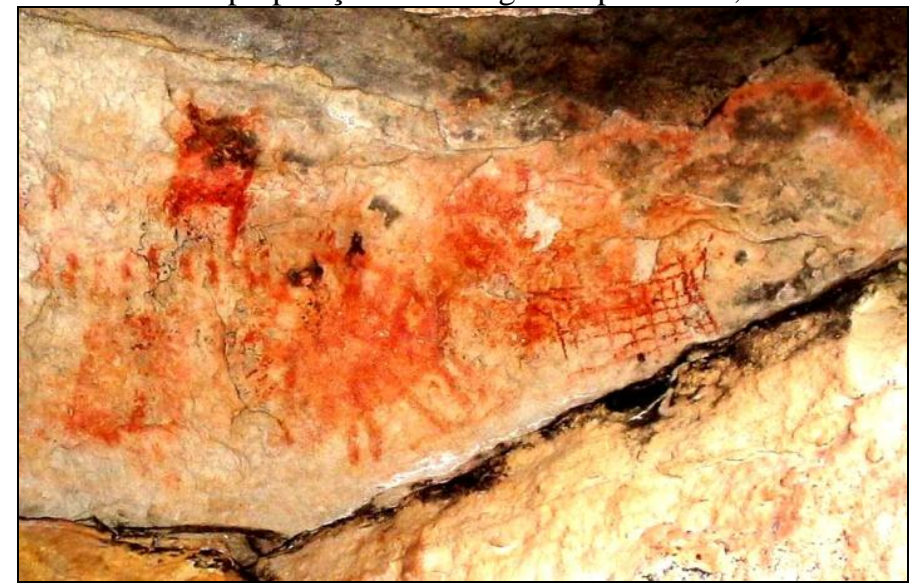

Foto: Parellada, 2009. 
Em vários abrigos no município de Tibagi podem ser observadas duas fases de pinturas de animais, em vermelho e marrom. A mais antiga caracteriza-se pela pintura chapada, com animais pequenos, muitas vezes enfileirados. A mais recente mostra silhuetas de animais, principalmente cervídeos, isolados. Entretanto, em outros sítios parece haver contemporaneidade dessas pinturas. Ainda nos municípios paranaenses de Tibagi e Ventania foram identificados abrigos com pinturas em vermelho com representação botânica, prováveis plantas cultivadas, como milho, associadas a bastonetes, figuras de contagem.

Parte dessas pinturas e gravuras rupestres, no Paraná, com datação entre quatro mil e duzentos anos atrás, parece estar relacionadas a povos Itararé-Taquara, ou seja, antepassados de grupos Jê (PARELLADA, 2003; 2006). Os Itararé-Taquara, ancestrais de indígenas Jê, chegaram em território paranaense há 4.000 anos, vindos do planalto central brasileiro, ocupando primeiro as terras altas do sul brasileiro, com possível troca genética com caçadores-coletores pré-existentes. Parte dos Itararé-Taquara demilitava os territórios marcando símbolos clânicos em abrigos rochosos e troncos do pinheiro Araucária. O uso de bastões cerimoniais, arcos, flechas e lanças decorados com elementos figurativos da memória mítica parece ser bastante recorrente, observar discussões em Parellada (2008).

Povos Itararé-Taquara cremavam os mortos, sepultando-os em danceiros ou abrigos rochosos, onde podiam ser elaborados painéis com pinturas e/ ou gravuras, que continham elementos míticos e da memória oral. Os Kaingang no século XIX, também chamados de Coroados, enterravam os mortos em estruturas subterrâneas cobertas com morrotes de terra, descritas em Manizer (2006) e Parellada (2006).

No vale do Tibagi tem-se sítios Itararé-Taquara, como a ocupação mais recente do Abrigo Morro do Castelo, onde a cerâmica aflorava na superfície (CHMYZ, 1976), e na Lapa Floriano foi coletada cerâmica Itararé entre 40 a 60cm (BLASI, 1972).

Parellada (2009) caracterizou o abrigo da Janela, em Sengés, com pinturas rupestres e sítio-acampamento Itararé-Taquara. As pinturas, no teto, são vermelhas, 2,5 YR 4/8, segundo tabela de Munsell, agrupam-se em três painéis: um com círculo raiado e pictoglifo danificado, o segundo com bastonetes e figuras chapadas, e o terceiro com três círculos e um cervídeo chapado. Talvez exista contemporaneidade das pinturas com 
a ocupação Itararé-Taquara, uma das fogueiras do abrigo da Janela foi datada pelo

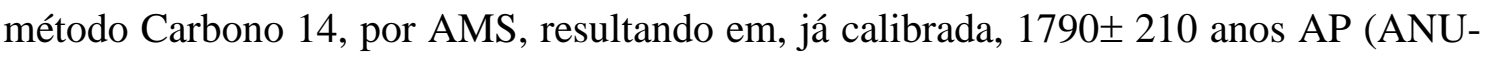
192-27).

O abrigo Jaguariaíva 1 situa-se em Jaguariaíva, medindo 17x 21x 5,20m, com no mínimo dois períodos diferentes de pinturas devido à ocorrência de superposições, e na área escavada no interior do abrigo foram recuperados vestígios de seis níveis de ocupação, o mais recente relacionado ao início do século $\mathrm{XX}$, os intermediários por agricultores e ceramistas Itararé-Taquara, e os dois mais antigos por caçadores-coletores Umbu (PARELLADA, 2009).

As pinturas do abrigo Jaguariaíva 1 apareciam na parede e no teto do abrigo, desde $0,5 \mathrm{~m}$ até $1,90 \mathrm{~m}$ de altura na face oeste, e de $1,80 \mathrm{~m}$ a $3,60 \mathrm{~m}$ na face norte. No principal painel no abrigo existem superposições de pinturas de animais e de grades, sendo as mais antigas figuras de cervídeos, em vermelho, preenchidas e chapadas, e as mais recentes figuras marrons, em silhueta, preenchidas por traços. Na face norte existe bastonetes, em vermelho, e figuras emblemáticas pontilhadas, em amarelo, que parecem estar associadas à segunda fase de pinturas. As pinturas mais recentes, pontilhadas, parecem estar correlacionadas a grupos ceramistas Itararé-Taquara, e as de figuras de animais chapadas a caçadores Umbu.

Aytai (1970) estudando abrigo, em Itapeva, relaciona aquelas pinturas e gravuras a grupos Jê. Dados etno-históricos dessa região, desde o século XVI e, principalmente, no XIX, descrevem a presença de indígenas Coroados ou Kaingang (NIMUENDAJU, 1993). Parte das pinturas rupestres no Paraná pode ser associada a povos ItararéTaquara, e talvez alguns pigmentos de pinturas sejam idênticos aos usados para colorir partes de tramas de cestos de taquara, pelos Kaingang, como os descritos por Fernandes (1941).

No abrigo do Mariano, localizado próximo a grande cachoeira, em Jaguariaíva, foram documentadas pinturas rupestres em vermelho, sendo cinco círculos, cada um com riscos ou pontos, que se assemelham às pinturas corporais clânicas de grupos Jê meridionais.

No abrigo São José da Lagoa 2, no município paranaense de Piraí do Sul, existe um painel complexo em diferentes tons de vermelho, com $0,5 \times 0,7 \mathrm{~m}$, completamente 
diferenciado dos já documentados no sul do Brasil, com mais de cem figuras humanas, em movimento, envolvidas por três grandes semicírculos (PARELLADA et al., 2014) (ver figura 1), e que pode estar relacionado a outros abrigos próximos com desenhos geométricos e figuras humanas associadas. O painel parece representar um mito Jê, maiores estudos na região poderão trazer novos elementos para ampliar as discussões, inclusive com o detalhamento da documentação da arte rupestre nos municípios paranaenses de Piraí do Sul, Tibagi e Ventania.

O painel maior do abrigo São José da Lagoa, em rochas areníticas, situa-se entre 6 e $7 \mathrm{~m}$ de altura, sendo que no topo da cena aparecem três seres fantásticos, animais humanizados, com dois dançando juntos e um terceiro maior com provável chocalho nas mãos.

Logo abaixo está uma fileira horizontalizada com 14 figuras humanas estilizadas como se estivessem dançando, com braços para baixo, e na ponta direita mais 8 figuras deitadas ou inclinadas situadas próximas de ondede termina uma grande linha diagonal que atravessa parte do painel. Todas as figuras desta fila parecem ter duas pontas grandes na cabeça, representando adornos ou uma transformação mítica.

Abaixo desta primeira fila está uma figura humana sozinha com os braços para cima, um provável xamã, e numa terceira fileira estão 11 indivíduos também com braços para cima. As figuras humanas das três primeiras fileiras possuem tamanho maior que as das duas fileiras mais baixas. A quarta fileira possui 33 indivíduos representados, e a quinta fileira tem 36 figuras humanas, todos com os braços para cima, e em movimento.

Todas as figuras são chapadas, menos as duas linhas, dois semicírculos, unidas por traços diagonais cruzados internos criando um desenho assemelhados a uma pele de cobra.

Essas duas linhas sustentam 23 cabeças galhadas de cervídeos masculinos, situadas abaixo da última fileira com figuras humanas. Observando essa parte do painel, da esquerda para a direita, os três primeiros pares de cabeças de cervídeos se olham, as duas cabeças subsequentes olham para a direita, as três posteriores para a esquerda, e as doze últimas para a direita, em direção de onde se encontram a grande linha diagonal com o grande semicírculo mais baixo que possui três fileiras próximas de pontas de 
tridentes semicirculares, que parecem encerrar um mundo diferenciado num momento mítico.

O abrigo apresenta películas com recristalização de caulinita e calcita sobre parte das pinturas, além de fraturas e escamação, o que dificulta a visualização completa desse painel espetacular. É possível verificar que existem no centro do painel algumas pinturas com linhas e traços, que podem ter sido pintadas em épocas diferenciadas.

Também é importante ressaltar que a conservação do abrigo São José da Lagoa 2, situado em propriedade particular, vem sendo buscada através de ações de educação patrimonial, que incluem a conscientização da comunidade regional, além de estudos para implantação de área de proteção ambiental, já que em locais próximos foram identificados outros sítios rupestres com características diferenciadas.

Os ancestrais dos índios Tupi e Guarani estavam no Paraná desde 2.000 anos atrás, provavelmente oriundos da porção central da Amazônia. Os Guarani, agricultores, viviam em aldeias, em grandes casas comunais, sendo que algumas representações da cerâmica Guarani parecem estar relacionados a cruz e a serpente, elementos mitológicos (TOCHETTO, 1996).

A confecção de cerâmica, e as diferentes decorações usadas, e de esculturas de elementos figurativos mitológicos em madeira, cera, resina de árvore e cerâmica, e as pinturas corporais e em tecidos eram as formas mais usuais de expressão simbólica desses grupos. Nigro et al. (1973) localizaram três sítios Tupiguarani que correlacionaram com gravuras geométricas e polidores em arenito, em Porto Amazonas, junto ao rio Monjolo, afluente do rio Iguaçu.

Historicamente as pinturas e gravuras rupestres que ocorrem no Paraná têm sido enquadradas em duas Tradições: Planalto e Geométrica. A Planalto apresenta grafismos pintados geralmente em vermelho ou marrom, e mais raramente em preto ou amarelo, algumas vezes em branco (PROUS, 1989). Geralmente animais são representados, aparecendo em menor proporção figuras humanas, grades, sinais geométricos e motivos emblemáticos; são frequentes as figuras estilizadas. A concentração das pinturas rupestres no Paraná está na área de afloramentos dos arenitos Furnas e Itararé, mas também aparecem no granito Três Córregos, em Cerro Azul, em abrigos em andesitos e basaltos em Foz do Jordão. 
A Tradição Geométrica caracteriza-se por apresentar representações geométricas, quase não aparecendo outros grafismos (RIBEIRO, 1978). Nela estão reunidas as gravuras rupestres encontradas no Paraná, já identificadas em rochas básicas nos vales dos rios Iguaçu e Paraná, em arenitos do município de Jacarezinho, em migmatitos de Guaratuba, e em parte das pinturas rupestres em abrigos nos arenitos Furnas e Itararé, principalmente em sítios do sul de São Paulo (AYTAI, 1970) e do centro-norte do Paraná (PARELLADA, 1997, 2003, 2006).

\section{AS GRAVURAS RUPESTRES NO PARANÁ}

As gravuras ocorrem em áreas de afloramentos de basaltos e andesitos da Formação Lavas da Serra Geral, de arenitos e conglomerados Furnas, de arenitos e diamictitos Itararé, de rochas metamórficas do Complexo Cristalino, de granitos da Serra do Mar e diques de diabásio.

Em algumas das gravuras rupestres já foram observados vestígios de pigmentos bastante intemperizados, ou seja, possivelmente parte delas era pintada, ou havia pinturas associadas. Como as gravuras geralmente ocorrem em afloramentos de rocha a céu aberto, acabam sendo mais susceptíveis ao intemperismo. Assim, para poder entender a arte rupestre como linguagem simbólica é interessante a discussão conjunta das técnicas, dos desenhos e da distribuição geográfica das gravuras e pinturas rupestres em regiões circunvizinhas.

Ainda é importante destacar a existência de muitos sítios com bacias de polimento e afiadores, distribuídos por todo o Paraná, alguns com gravuras associadas, como os existentes no município de Porto Amazonas, alguns compondo o acervo do Museu Paranaense.

Bacias de polimento e afiadores eram relativamente comuns nos grandes afloramentos de rocha existentes em áreas costeiras, como Morretes, Antonina, Matinhos e Guaratuba, alguns associadas a sambaquis (BIGARELLA, 2011; FERNANDES; BANDEIRA, 2014), porém parte foi danificada e/ ou destruída por ações antrópicas. Leão (1926) descreve gravuras rupestres geométricas no município de Antonina, talvez históricas. 
Rosane Fernandes e Marcos Wasilewski, em 2013, caracterizaram gravura, círculo raiado, no município de Guaratuba, litoral sul do Paraná. Em costões rochosos das ilhas da Pescaria e da Sepultura, também em Guaratuba, nas proximidades de sambaquis, foram identificadas várias bacias de polimento (BIGARELLA, 2011).

Sambaquis são acumulações artificiais principalmente de conchas de moluscos e gastrópodos, restos faunísticos, com materiais orgânicos associados, e variados processos de formações e populações associadas. Parte deles, com maior visibilidade devido o volume, caracteriza-se como grandes aterros, inclusive com formas geométricas e de animais, com grande quantidade de sepultamentos e possíveis áreas cerimoniais.

Em sambaquis de Matinhos, Antonina, Paranaguá e Pontal do Paraná recuperaram-se zoólitos, esculturas em diabásio, gnaisse e granito, principalmente em forma de pássaros, mamíferos, répteis, entre outros, além de zoósteos (TIBURTIUS; BIGARELLA, 1960; GOMES, 2012).

No vale do médio Iguaçu foram caracterizadas as gravuras nos sítios Vargem Grande (CHMYZ, 1968) e Abrigo Bruacas (CHMYZ, 1969), associadas a ceramistas Itararé-Taquara. No Bruacas, situado na escarpa basáltica, em União da Vitória, no sul do Paraná, existem conjuntos de círculos formando alinhamentos paralelos. Os círculos tem diâmetro médio de $2 \mathrm{~cm}$ e cerca de $5 \mathrm{~mm}$ de profundidade, e outros conjuntos apresentavam sulcos alongados, como os causados geralmente pelo polimento de artefatos.

Langer e Santos (2001) caracterizaram mais três sítios com gravuras no médio Iguaçu: Caverna do Alemão em Porto União, Santa Catarina, e no Paraná: Morro das Tocas em União da Vitória, e Sítio Pedra Fincada em Cruz Machado. O Pedra Fincada possui quatro conjuntos representando círculos e linhas sinoidais, e um com grafismos históricos.

Em Jacarezinho, norte do Paraná, Robrahn-González (1995) cadastrou um abrigo arenítico, com gravuras, em baixo relevo, em 30m de extensão, e com diferentes motivos, principalmente geométricos. Predominam tridígitos, ocorrendo traços cruzados em "xis", estrelas, traços paralelos verticais cortados por horizontais, losangos e "ziguezagues". 
No vale do Iguaçu, junto ao sítio arqueológico Ouro Verde I, sudoeste paranaense, foi caracterizado um conjunto de 500 gravuras rupestres, em afloramentos e blocos de basaltos e andesitos, predominando representações geométricas, com círculos concêntricos e pontos centrais, alguns raiados, muitos pontos formando linhas e grades (PARELLADA, 2006) (ver figura 4). Os círculos gravados tem diâmetros que variam de 1 a $24 \mathrm{~cm}$, e profundidades entre 0,6 e $3,5 \mathrm{~cm}$. Parte dessas gravuras pode estar relacionada a uma das ocupações mais antigas do Paraná, o nível inferior do sítio Ouro Verde I, datado em 9040 400 anos AP (ANU 192-17), relacionado a caçadorescoletores Umbu. Nesse sítio também ocorrem vestígios mais recentes de ceramistas Itararé-Taquara, datados em cerca de 300 anos atrás.

Em Três Barras do Paraná, na margem direita do Iguaçu, foi cadastrado o sítio Cruz Alta 1, com 50 gravuras em afloramentos e blocos de basalto, onde aparecem círculos concêntricos e pontos com profundidades maiores que os de Ouro Verde (PARELLADA, 2006).

Merencio e Souza (2011) relacionam três sítios com gravuras rupestres relacionadas à Tradição Geométrica, especialmente no município de Capitão Leônidas Marques, quando das prospecções do Programa Arqueológico da UHE Baixo Iguaçu.

No município de Toledo, junto ao rio São Francisco, oeste paranaense, em área do eixo da barragem PCH São Francisco foram identificadas várias gravuras rupestres, principalmente círculos concêntricos.

$\mathrm{Na}$ área da cachoeira dos Apertados, foi identificado o sítio Recanto Apertados Piquiri I, no município paranaense de Formosa do Oeste. Foram registrados bacias de polimento, afiadores e gravuras rupestres, em afloramentos de rochas básicas nas margens do Piquiri. As gravuras medem entre 2 a $15 \mathrm{~cm}$, sendo sulcos alongados, representações geométricas, circulares a elípticas, com profundidades entre 0,5 e $1,5 \mathrm{~cm}$ (PARELLADA, 2013).

\section{DOCUMENTANDO E VISUALIZANDO A ARTE RUPESTRE}

As lentes polarizadas, usadas em máquinas fotográficas ou em lentes escuras de óculos de sol, entre outras possibilidades, podem auxiliar na diminuição do brilho 
incidente na arte rupestre, diminuindo o reflexo da luz, trazendo maior contraste e nitidez da imagem, como pode ser observado em figura de pequeno cervídeo em parede do abrigo Chapadinha II, que está em área com grande exposição de luz. A correção da luz traz uma visualização mais rápida de imagens expostas com grande luminosidade, além de possibilitar maior conforto visual para um trabalho que requer melhor acuidade visual.

Imagens de satélite, algumas atualizadas e disponíveis pelo Google Maps, foram e continuam sendo de extrema importância para a análise e o monitoramento de sítios arqueológicos, especialmente os com arte rupestre. A possibilidade de diferentes inclinações

O uso de drones, veículos aéreos não tripulados e com controle remoto, tornam a documentação de locais de difícil acesso mais rápida, segura, e em muitos casos, com maior economia de recursos. Esta tecnologia vem diminuindo de custo na medida do aumento do seu uso pelas equipes de arqueologia no mundo.

Técnicas interessantes e com melhores recursos tecnológicos para a documentação imagética são: o scanner laser 3D, a tomografia computadorizada por raio X, e o mapeamento de texturas polinomial (Polynomial Texture Mapping - PTM), além das fotografias em 3D, conforme Payne (2012), que destaca a diferença de custos no uso de cada técnica.

O melhor custo/ benefício para o detalhamento de pinturas e gravuras rupestres parece estar no PTM e nas fotografias em 3D em máquinas digitais. $\mathrm{O}$ escaneamento a laser em 3D em abrigos e cavernas traz um mapeamento topográfico com resultados excepcional para a análise e caracterização espacial de painéis e figuras.

O PTM consiste em tirar diversas fotografias de um mesmo painel ou figura com diferentes direções de iluminação, quanto maior o número melhor é o resultado, sendo que um programa junta as imagens e assim é possível selecionar o melhor ângulo de iluminação, observar a documentação de gravuras em Urubici, Santa Catarina, por Riris e Corteletti (2015).

Muitas pinturas rupestres em abrigos e cavernas nos arenitos Furnas, nos Campos Gerais do Paraná, as mais recorrentes no Paraná, estão parcialmente cobertas por caulinita, pois conforme Melo e Giannini (2007) o cimento argiloso diagenético 
destes arenitos é dissolvido e reprecipitado na forma de caulinita criptocristalina ou em microfissuras.

Existem diferentes técnicas e métodos arqueométricos que podem colaborar na identificação dos pigmentos e fixadores usados nas pinturas rupestres, e dos agentes intempéricos atuantes.

Associados aos vestígios materiais recuperados em subsuperfície de abrigos, com pinturas rupestres, são frequentes as concreções argilosas ricas em ferro, além da hematita e goethita, muitas vezes usadas para compor os pigmentos vermelhos e amarelos, e o manganês associado à matéria orgânica para o preto (APPOLONI et al. 2010; 2011; 2014a,b).

A identificação dos pigmentos das pinturas pode ser feita através da coleta de fragmentos de suporte rochoso com pinturas, já soltos do conjunto, superficiais ou recuperados em escavações arqueológicas. Essas pinturas podem ser analisadas em laboratórios, segundo as técnicas convencionais, como a fluorescência por raio-X ou a espectroscopia Raman, entre outras. Porém, a maior parte das pinturas rupestres no Paraná se encontra associada ao suporte rochoso, o que torna necessário o uso de equipamentos portáteis, como foram os estudos realizados no abrigo Jaguariaíva I, no município de Jaguariaíva, e nas Cavernas de Morro Azul, no município de Ventania, Paraná (APPOLONI et al. 2010; 2011; 2014b).

A análise das figuras, no sudeste do Piauí, mostrou que é importante que se faça a coleta em dois ou três pontos diferentes da mesma figura, procurando verificar as diferenças composicionais em uma mesma pintura, e ainda evidenciar a presença de elementos maiores, menores e traços (SOARES MENESES LAGE, 1997).

O estado de conservação das pinturas pode ser detectado por filmes infravermelhos e/ ou ultravioletas, associados a filtros coloridos, como o laranja, o amarelo e o vermelho. Além disso, o grau de alteração pode ser observado também pela análise macroscópica, e mesmo por outros métodos físicos não destrutivos que detectem uma variação superficial encobrindo, total ou parcialmente, as pinturas rupestres. 


\section{CONCLUSÕES}

Novas pesquisas e tecnologias de documentação imagética vêm possibilitando caracterizar um grande mosaico com diferentes sociedades relacionadas à arte rupestre no Paraná, sul do Brasil. A caracterização de painéis complexos com muitas figuras humanas, e a representação de plantas cultivadas, além da clara associação de parte das pinturas e gravuras com populações Jê meridionais amplia as discussões regionais.

Os povos pintavam e gravavam nas rochas buscando delimitar o território, expressar a complexidade das culturas, evidenciar as relações com o ambiente que ocupavam e marcar elementos míticos presentes no imaginário social.

A conservação dos sítios rupestres, inclusive em unidades de conservação já estabelecidas como o Parque Estadual do Guartelá e de Vila Velha, é fundamental para possibilitar a visualização desta memória estética e simbólica do Paraná.

A implementação de maiores estratégias para diminuir os impactos nos sítios com arte no Paraná são urgentes e necessárias, tais como:

- aumentar ações de educação patrimonial com visitantes, monitores e a comunidade local;

- ampliar a segurança, com mais equipamentos e recursos tecnológicos, inclusive vigilância remota por câmeras;

- restringir os acessos a abrigos com pinturas, inclusive com número máximo de visitantes por guia e/ ou monitor;

- informar imediatamente a Superintendência Regional do IPHAN no Paraná, quando da identificação de dano ao patrimônio arqueológico, possibilitando maior agilidade na proteção e preservação destes bens culturais;

- realizar análises com técnicas nucleares não destrutivas para melhor caracterizar os pigmentos, fixadores, técnicas de execução das pinturas, grau de alteração, possibilitando a proposição de medidas mais eficazes na conservação e gerenciamento da arte rupestre;

- fazer o monitoramento das áreas através de imagens de satélite e de drones para uma detecção rápida de interferências antrópicas e/ ou processos erosivos que possam comprometer a estabilidade de sítios rupestres, especialmente em parques estaduais; 
- ampliar o estudo e a localização de novos sítios arqueológicos.

\section{REFERÊNCIAS}

APPOLONI, C.R.; LOPES, F.; MELQUÍADES, F.; PARELLADA, C.I. In situ pigments study of rock art Jaguariaíva I archaeological site (Paraná, Brasil) by portable energy dispersive x-ray fluorescence (edxrf). FUMDHAMentos, v. 9, p. 555-562, 2010.

APPOLONI, C.R.; PARELLADA, C.I.; MELQUÍADES, F.L.; JUSSIANI, E.I.; PEREIRA, F.C.; LOPES, F. The first in situ portable Raman and XRF study of rock art in South America: paintings from Morro Azul caves in Paraná State, Brazil. In: 6 INTERNATIONAL CONGRESS ON THE APPLICATION OF RAMAN SPECTROSCOPY IN ART AND ARCHAEOLOGY, Parma. Abstracts... 2011, p.98.

APPOLONI, C.I.; PARELLADA, C.I.; JUSSIANI, E.I.; MELQUÍADES, F.L.; OLIVEIRA, F.C.P. Rock art paintings of Chapadinha shelters, Paraná State, Brazil - na in situ Raman study. In: X SIMPÓSIO INTERNACIONAL DE ARTE RUPESTRE, Anais... Teresina: ABAR, CNPq, CAPES, UFPI, 2014a, p.18.

APPOLONI, C.I.; PARELLADA, C.I.; JUSSIANI, E.I.; LOPES, F.; MELQUÍADES, F.L.; OLIVEIRA, F.C.P. Portable X-ray fluorescence and Raman spectroscopy for in situ rock art analysis. In: X SIMPÓSIO INTERNACIONAL DE ARTE RUPESTRE, Anais... Teresina: ABAR, CNPq, CAPES, UFPI, 2014b, p.124.

ARNT, F.V. As pinturas rupestres como testemunho de ocupação pré-contato em Tibagi, Paraná. Monografia (Graduação), História, UNISINOS, São Leopoldo, 2002.

AYTAI, D. As gravações rupestres de Itapeva. Revista da Universidade Católica de Campinas, Campinas, v.3, 14, p. 29- 61, 1970.

BARBOSA, J.N.A. Arte rupestre: a história que a rocha não deixou apagar. Curitiba, JNA Barbosa, 2004.

BEHLING, H.; PILLAR, V.D.P.; ORLÓCI, L.; BAUERMANN, S.G. Late Quaternary Araucaria forest, grassland (Campos), fire and climate dynamics, studied by highresolution pollen, charcoal and multivariate analysis of the Cambará do Sul core in southern Brazil. Palaeogeography, Palaeoclimatology, Palaeoecology, v.203, n.3-4, p.277-297. 2004.

BIGARELLA, J.J. (Org.). Sambaquis. Curitiba, Posigraf, 2011.

BLASI, O. Aspectos da arte pré-histórica no sul do Brasil. In: VALCAMONICA SYMPOSIUM INT. D'ART PRE-HISTORIQUE, Capo di Ponte. Actes... 1970, p.461465. 
BLASI, O. Cultura do índio pré-histórico. Vale do Iapó, Tibagi- PR. Arquivos do Museu Paranaense, nova série arqueologia, Curitiba, n.6, 1972.

BLASI, O. et al. Projeto de levantamento e cadastramento de sítios arqueológicos do $2^{\mathbf{0}}$ planalto paranaense. Curitiba: SEEC-PR (relatório interno), 1991.

BLASI, O.; PONTES, A.; MULLER, C.R.M. Apreciação resumida sobre a arte rupestre nos Campos Gerais do Paraná. Fumdhamentos, São Raimundo Nonato, v.1, n.2, p. 209-218, 2002.

CAVAlHeirO, A.C.M. Pinturas rupestres dos Campos Gerais - Paraná. 143f. Dissertação (Mestrado) - Arqueologia, FFCLH, USP, São Paulo, 2004.

CHMYZ, I. Breves notas sobre petroglifos no segundo Planalto Paranaense (Sítio PR UV 5). Revista do CEPA-UFPR, Curitiba, n.1, p. 53-63, 1968.

CHMYZ, I. Novas manifestações da tradição Itararé no Estado do Paraná. Pesquisas, Antropologia, São Leopoldo, n. 20, p. 121-129, 1969.

CHMYZ, I. Nota prévia sobre o sítio PR PG 1: abrigo sob rocha Cambiju. Estudos Brasileiros, Curitiba, v.2, p. 231-246, 1976.

CHMYZ, I.; SGANZERLA, E.M.; VOLCOV, J.E.; BORA, E.; CECCON, R.S. A arqueologia da área da LT 750kV Ivaiporã- Itaberá III, Paraná- São Paulo. Arqueologia, Revista do CEPA-UFPR, Curitiba, número especial, v.5, p.1-305, 2008

FERNANDES, R.P.; BANDEIRA, D.R. Potencialidades da musealização de sítios arqueológicos: caso da APA de Guaratuba - PR. Revista Museologia e Patrimônio, Unirio-MAST, Rio de Janeiro, v. 7, n. 1, p. 77-94, 2014.

GAISSLER, M. (Coord.). Levantamento, cadastramento e proteção de sítios arqueológicos nas áreas de reserva legal, preservação permanente e plantio florestal da Empresa Stora Enso Empreendimentos Agrícolas Ltda. Relatório Técnico, Curitiba: Ygaribá, 2007.

GOMES, A.A.O. Perspectivas interpretativas no estudo das esculturas zoomórficas pré-coloniais do litoral sul do Brasil. 244p. Dissertação (Mestrado), Antropologia, UFPR, 2012.

GOMES, C.S. As representações geométricas e zoomorfas da Tradição Planalto. Curitiba: SEEC-PR, 2011.

GOTTARDI NETO, A. Análise cerâmica do projeto Cavernas de Morro Azul. Revista do Museu de Arqueologia e Etnologia, São Paulo, v.5, p. 63-75, 1995.

HODDER, I. Interpretación en arqueologia, corrientes actuales. Barcelona: Crítica, 1988. 
HODDER, I. (Ed.) Religion in the emergence of civilization: Çatalhoyuk as a case study. New York: Cambridge University Press, 2010.

JORGE, M., PROUS, A.; RIBEIRO, L. Brasil rupestre: arte pré-histórica brasileira. Curitiba: Zencrane Livros, 2007.

LAMING, A.; EMPERAIRE, J. Decouvertes de peintures rupestres sur les hauts plateaux du Paraná. Journal Soc. Americanistes, Paris, n. XLV, p. 165-178, 1956.

LAMING-EMPERAIRE, A. Travaux arquéologiques en Amerique du Sud. Objets et Mondes, Paris, v.2, n.3, p. 149-164, 1962.

LAMING-EMPERAIRE, A. Missions arquéologiques françaises au Chili Austral et au Brésil Méridional: Datation de quelques sites par le radiocarbone. Journal Soc. Americanistes, Paris, v.67, p. 77-99, 1968.

LANGER, J.; SANTOS, S.F. Petróglifos do médio rio Iguaçu. Rupestre/ web. Disponível em: http://rupestreweb.tripod.com/iguazu.html. Acesso em: jun. 2001.

LEÃO, E. A. Antonina: factos e homens: da idade archeolíthica à elevação à cidade. Curitiba: F. J. Gonçalves, 1926.

LIMA, M.A.; JUSTO, G.M. A memória no canyon Guartelá: uma discussão sobre aspectos pré-históricos e históricos do vale do rio Iapó. Monografia graduação História. Ponta Grossa, Universidade Estadual de Ponta Grossa, 2002.

MARANHÃO, M.F.C.; PARELLADA, C.I. Relatório preliminar do Projeto Arqueológico Sengés. Curitiba: Museu Paranaense- IPHAN, Rel. interno, 1991.

MELO, M.S.; GIANNINI, P.C.F. Sandstone dissolution landforms in the Furnas Formation, southern Brazil. Earth surface processes and landforms, v. 32, p. 21492164, 2007.

MERENCIO, F.T.; SOUZA, J.G. Prospecção arqueológica no baixo rio Iguaçu (PR): resultados e perspectivas de pesquisas. In: BARCELOS, A.H.; PARELLADA, C.I.; CAMPOS, J.B. (Org.) Arqueologia do sul do Brasil. Criciúma: UNESC, p.343-364, 2011.

MORO, R.S. (Org.). Biogeografia do cerrado nos Campos Gerais. Ponta Grossa, Editora UEPG, 2012.

NAUMES, V.M.; SPOLADORE, A. Resultados preliminares do estudo do abrigo Mocambo 6, Sengés, Paran. In: 28 CONGRESSO BRASILEIRO DE ESPELEOLOGIA. Anais... Campinas: SBE, 2005. 
NIGRO, L.H.F. et al. Projeto Porto Amazonas. Dédalo, São Paulo, v. 17-18, p. 100, 1973.

NIMUENDAJU, C. Etnografia e indigenismo: sobre os Kaingang, os Ofaié-Xavante e os índios do Pará. Campinas: Ed. Unicamp, 1993.

OLIVEIRA, F.C.P. Abrigos com pinturas rupestres em Piraí da Serra - Paraná: uma abordagem geoarqueológica. Dissertação (Mestrado), Geografia, UFPR, Curitiba, 2014.

PARELlADA, C.I. Relatório final do projeto Cavernas de Morro Azul. Museu Paranaense/ Fundação Boticário de Proteção à Natureza, Curitiba, 1993 a.

PARELLADA, C.I. As pinturas rupestres em Morro Azul/ Ventania- PR. In: 6 REUNIÃO CIENTÍFICA DA SAB. Boletim de Resumos... João Pessoa: Editora UFPB, p.68, 1993 b.

PARELLADA, C.I. (Coord.). Projeto manejo e conservação de cavernas nos municípios de Sengés, Dr. Ulysses e Cerro Azul-PR. Curitiba: Museu Paranaense Boticário, 1994.

PARELLADA, C.I. Caracterização do patrimônio arqueológico do Parque Estadual Canyon do Guartelá. Curitiba: Museu Paranaense/ IAP (relatório inédito), 50p, 2000.

PARELLADA, C.I. Pinturas rupestres no centro-leste e nordeste paranaense. In: 12 CONGRESSO DA SAB. Anais... São Paulo: SAB, 2003.

PARELLADA, C.I. Estudo arqueológico no alto vale do rio Ribeira: área do gasoduto Bolívia-Brasil, trecho X, Paraná. 2005, 271p. Tese (Doutorado), Arqueologia, MAE, USP, São Paulo, 2006.

PARELLADA, C.I. Arqueologia dos Campos Gerais. In: MELO, M.S.; MORO, R.S.; GUIMARÃES, G. B. Patrimônio Natural dos Campos Gerais do Paraná. Ponta Grossa: Editora UEPG, p. 163-170, 2007

PARELLADA, C.I. Estética indígena Jê no Paraná: tradição e mudança no acervo do Museu Paranaense. Revista Científica da FAP, Curitiba, v.3, p. 213-229, 2008.

PARELLADA, C.I. Arte rupestre no Estado do Paraná. Revista Científica da FAP, Curitiba, v.4, n.1, p. 73-98, 2009. 
PARELLADA, C.I. (Coord.). Caracterização do patrimônio arqueológico de Piraí da Serra, municípios de Piraí do Sul e Tibagi, Paraná. Curitiba: Museu Paranaense, 57p., 2010.

PARELLADA, C.I. Arqueologia do vale do rio Piquiri, Paraná: paisagens, memórias e transformações. Revista Memorare, Tubarão, v. 1, p. 24-42, 2013.

PARELLADA, C.I. Gerenciamento de sítios rupestres e turismo cultural no Paraná, sul do Brasil. In: X SIMPÓSIO INTERNACIONAL DE ARTE RUPESTRE, Anais... Teresina: ABAR, CNPq, CAPES, UFPI, 2014a, p.51.

PARELLADA, C.I.; BARBOSA, A.; PEREIRA, E.M. Análise ambiental e estratigráfica do sítio arqueológico Ouro Verde I/ Boa Esperança do Iguaçu- PR. In: 39 CONGRESSO BRASILEIRO DE GEOLOGIA. Boletim de resumos ... Salvador: SBG. p.510-513, 1996.

PARELLADA, C.I.; CREMONEZE, C.; BATTISTELlI, E.; SARAIVA, M.P. Vida indígena no Paraná: memória, presença, horizontes. Curitiba: Provopar Ação Social, 2006.

PARELlADA, C.I.; GOTTARDI NETO, A. Abrigo do Pontão: análise do material lítico e cerâmico. In: 5 REUNIÃO CIENTÍFICA DA SAB. Resumos... Rio de Janeiro: $\mathrm{SAB}, 1991$.

PARELLADA, C.I.; OLIVEIRA, F.C.P.; SCLVILZKI, E.S. As pinturas rupestres do abrigo São José da Lagoa 2, Piraí do Sul, Paraná, Brasil. In: X SIMPÓSIO INTERNACIONAL DE ARTE RUPESTRE, Anais... Teresina: ABAR, CNPq, CAPES, UFPI, 2014, p.76.

PAYNE, E.M. Imaging techniques in conservation. Journal of Conservation and Museum Studies, London, v.10, n.2, p.17-29, 2012.

PEREIRA, F.C. As pinturas rupestres na região de Piraí da Serra - Paraná. Ponta Grossa, Monografia (Graduação), Curso de Geografia. Ponta Grossa, UEPG, 2009.

PEREIRA, F.C. Espacialização dos abrigos areníticos com pinturas rupestres em Piraí da Serra, Paraná. In: 31 CONGR. BRAS. ESPELEOLOGIA. Anais... Ponta Grossa: SBE, 2011.

PREUCEL, R.W. Archaeological semiotics. Oxford: Blackwell Publishing, 2006.

PREUCEL, R.W.; HODDER, I. (Ed.). Contemporary archaeology in theory: a reader. Oxford: Blackwell Publishing, 1996.

PROUS, A. Arqueologia brasileira. Brasília: Ed. UnB, 1992. 
RIBEIRO, P.M. A arte rupestre no sul do Brasil. Revista CEPA, v.7, p. 1-27, 1978.

RIRIS, P.; CORTELETTI, R. A new record of pre-Columbian engravings in Urubici (SC), Brazil using polynomial texture mapping. Internet Archaeology, 38. 2015.

ROBRAHN-GONZÁLEZ, E.M. A ocupação ribeirinha pré-colonial do médio Paranapanema. Revista do Museu de Arqueologia e Etnologia, USP, São Paulo, v.5, p. $99-116,1995$.

SILVA, A.G.C.; MELO, M.S.; PARELLADA, C.I. Pinturas rupestres em abrigo sob rocha no sumidouro do rio Quebra-Perna, Ponta Grossa, Paraná. Publicatio, Ciências Exatas Terra, UEPG, Ponta Grossa, v.12, n.1, p. 23-31, 2005.

SILVA, A.G.C.; PARELlADA, C.I.; MELO, M.S. Pinturas rupestres do sítio arqueológico abrigo Usina São Jorge, Ponta Grossa, Paraná. Publicatio, Ciências Exatas Terra, UEPG, Ponta Grossa, v.13, n.1, p. 25-33, 2007.

SOARES MENESES LAGE, M.C. Análise química de pigmentos de arte rupestre do sudeste do Piauí. Revista do Museu de Arqueologia e Etnologia, São Paulo, Supl. 2, p.89-101, 1997.

TIBURTIUS, G.; BIGARELLA, J.J. Objetos zoomorfos do litoral de Santa Catarina e Paraná. Pesquisas: Antropologia, São Leopoldo, v.7, p. 1-51, 1960.

TRIGGER, B. História do pensamento arqueológico. São Paulo: Odysseus, 2004.

VIALOU, D. L'art paléolithique. In: OTTE, M. (ed). La préhistoire. Paris: De Boeck Université. p.213-351, 1999.

VIALOU, D. Territories et cultures préhistoriques: fonctions identitaires de l'art rupestre. In: Kern, A.A. (org). Sociedades Íbero-Americanas: reflexões e pesquisas recentes. Porto Alegre: EDIPUCRS, p.381-396, 2000. 